\title{
Model predictive control of multilevel cascaded converter with boosting capability - a simulation study
}

\author{
P. WIATR* and M.P. KAZMIERKOWSKI
}

Electrotechnical Institute, 28 Pożaryskiego St., 04-703 Warsaw, Poland

\begin{abstract}
This paper presents a multilevel cascaded H-bridge 5-level converter with boosting capability. The standard solution for boosting voltage in power electronic devices is based on a DC-DC converter with a bulky inductor. However, inductor is a problematic component of a power electronic converter because usually it has to be individually designed and produced for every device and also because its size and weight do not allow for compact construction. This paper presents model predictive control (MPC) method that gives boosting capability for the presented converter. A novel contribution of this paper is the development of a predictive model of the converter and cost function enabling output current control and capacitor voltage balancing.
\end{abstract}

Key words: cascaded H-bridge (CHB), model predictive control (MPC), multilevel converters.

\section{Introduction}

With the increasing number of possible application of power electronic devices the requirements for power electronic converters systematically grow. Growing energy demand pushes converters to work with higher voltages and powers. Renewable energy sources call for higher efficiency and reliable converters. Electrical and Hybrid Vehicles need light and compact devices that will be easy to fit within a drive system. To find an answer to those rising problems a new converter topologies must be introduced and studied [1].

To overcome limitations of classical converter solutions, a family of multilevel converters have been introduced and studied for few last decades. They present great advantages compared with typical two-level converters. The main advantages can be listed out:

- lower output voltage distortion (lower THD),

- lower switching losses,

- lower $\mathrm{dV} / \mathrm{dt}$ in output voltage.

The three main topologies within multilevel converter family are $[1,2]$ :

- diode clamped converter (DCC),

- flying capacitor (FC),

- cascaded H-bridge converter (CHB).

Most research works on multilevel converters have been focused on the first two converter topologies DCC and FC, and there are fewer papers concerning CHB. Lower attention among researchers concerning Cascaded H-bridge Converter have been most likely caused by the well-known fact that each $\mathrm{H}$-bridge needs its own, separate DC source. Despite the aforementioned problem, $\mathrm{CHB}$ can be very attractive because of the following assets:

- possible modular design of a converter,

*e-mail: p.wiatr@iel.waw.pl
- high number of generated voltage levels compared to a number of components used,

- better DC utilization as compared to other multilevel topologies.

Recently, many researchers focus their work on another branch of multilevel converters which goes beyond a classical division and is called hybrid converters [1-4]. Hybrid converters integrate more than one converter topology into one. Every new solution has different parameters, states of operation and limitations that need to be examined. This leads to a new complex control algorithms that need to be studied and utilized in a multilevel converter family.

This paper is focused on investigation of a novel hybrid converter topology - 5-level cascaded H-bridge converter (5LCHB) with only one DC source, controlled with model predictive controller (MPC). The 5LCHB converter with PWM Control Method and fundamental switching scheme were presented in $[4,5$, 10-13]. According to [5], 5LCHB topology with a fundamental frequency switching is able to boost output AC voltage.

This solution overcomes one of the biggest disadvantages of multilevel cascaded converters, which is the requirement of separate DC source for each H-bridge used in a converter. This topology proposes a solution utilizing capacitors instead of a separate DC source. In this case, the MPC algorithm has to regulate output current and capacitor voltage. A new contribution by this paper is the development of a predictive model of the 5LCHB converter, formulation of the cost function for MPC algorithm and verification by a simulation study.

Simulation study shows that 5LCHB with MPC can output a boosted ac voltage. According to $[5,11]$, this feature can be used in hybrid electric vehicles (HEV) and electric vehicles (EV) drive system for elimination of a DC-DC boost converter that utilizes a heavy and bulky inductor. Another application of 5LCHB, according to [6], can be renewable energy sources because it can provide high volt-ampere ratings. Its boosting capability can also bring a greater flexibility to the system. 


\section{2. $5 \mathrm{LCHB}$ converter}

This research paper presents a hybrid version of 5-level CHB converter with 3 phase bridge converter depicted in Fig. 1. The proposed converter uses a standard 3-leg converter and a H-bridge in series with each converters leg. Each H-bridge uses a capacitor as a DC power source.

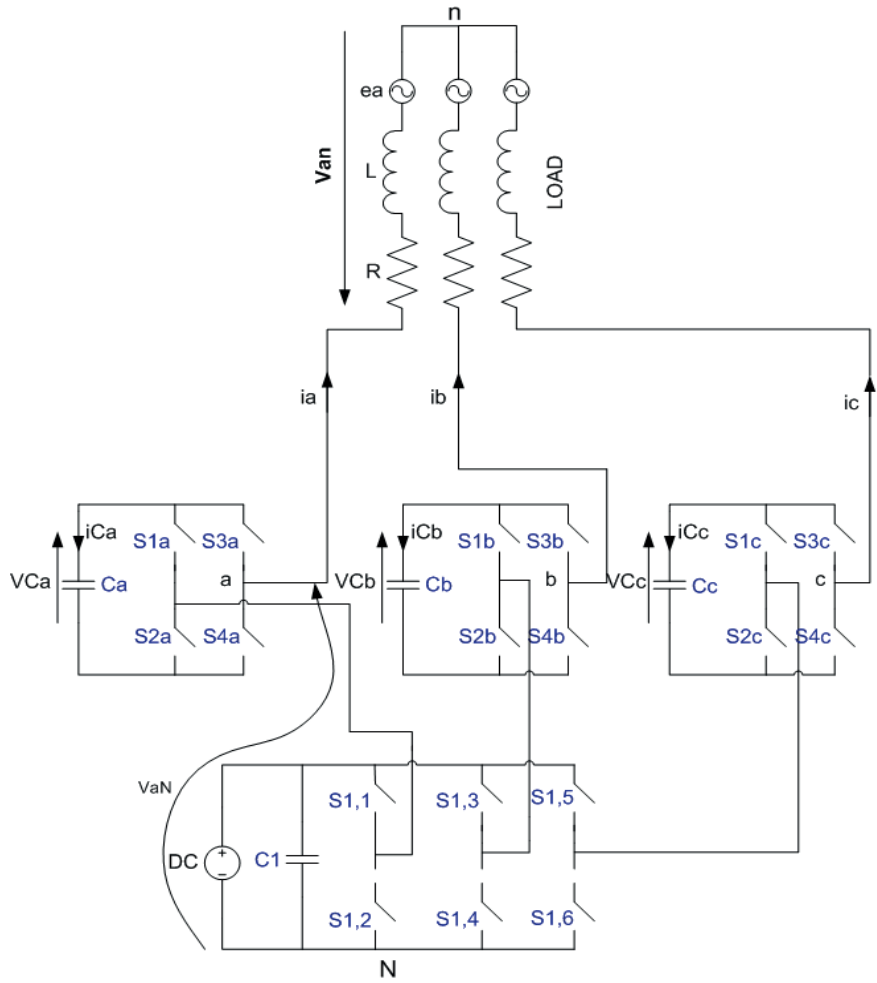

Fig. 1. Topology of the 5-level cascaded H-bridge converter (5LCHB)

In order to better explain the operation principles, a simplified single phase topology of a converter is shown in Figs. 2-6. The output voltage VP of a half-bridge is either +VDC/2 (switch $\mathrm{S} 1$ closed) or $-\mathrm{VDC} / 2$ (switches S1, S2 closed). Assuming that a capacitor $\mathrm{C}$ is kept charged to $\mathrm{VDC} / 2$, the H-bridge output voltage can take values +VDC/2 (switch S1a and S4a closed), 0 (switch S1a and S3a closed or S2a and S4a closed), or -VDC/2 (switches S2a and S3a closed).

It can be seen that the converter produces 5-level output waveform with voltage: +VDC, +VDC/2, $0,-\mathrm{VDC} / 2,-\mathrm{VDC}$.
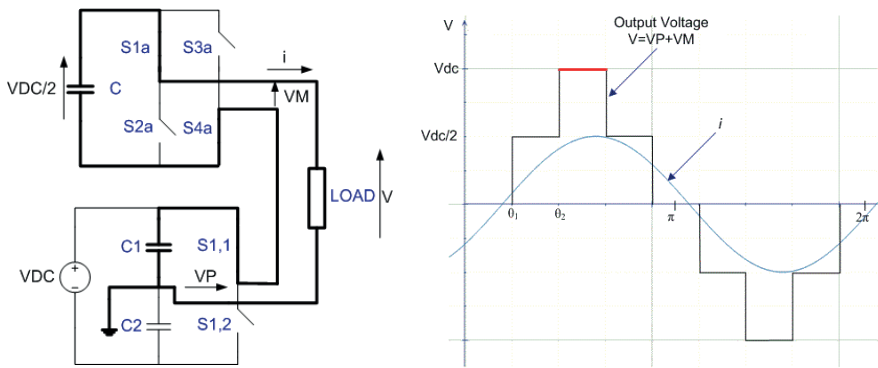

Fig. 2. Generation of a positive output voltage $V=V D C$
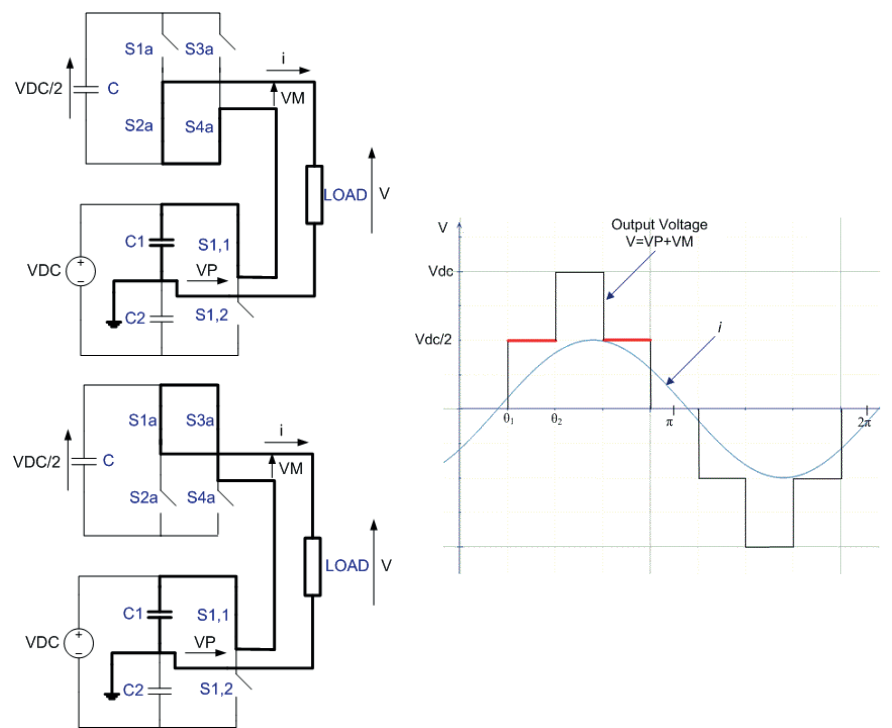

Fig. 3. Generation of a positive output voltage $\mathrm{V}=\mathrm{VDC} / 2$
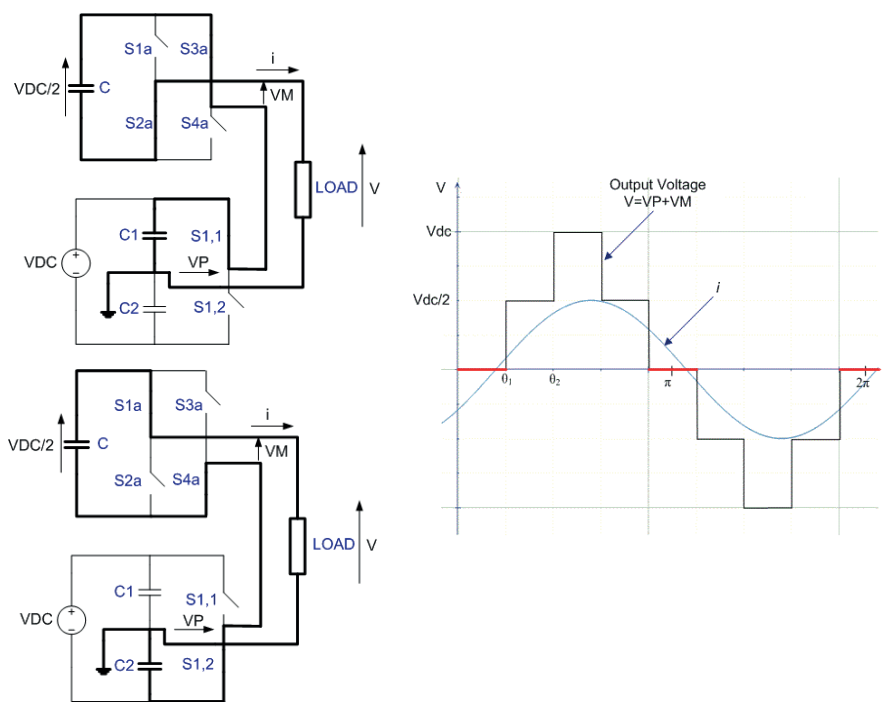

Fig. 4. Generation of an output voltage $\mathrm{V}=0$
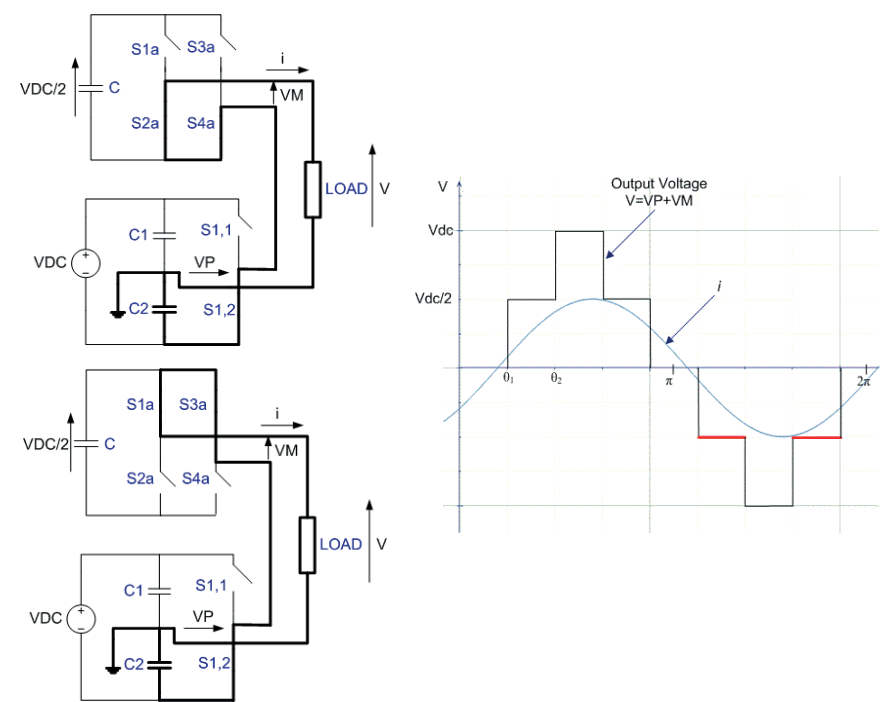

Fig. 5. Generation of a positive output voltage $\mathrm{V}=-\mathrm{VDC} / 2$ 

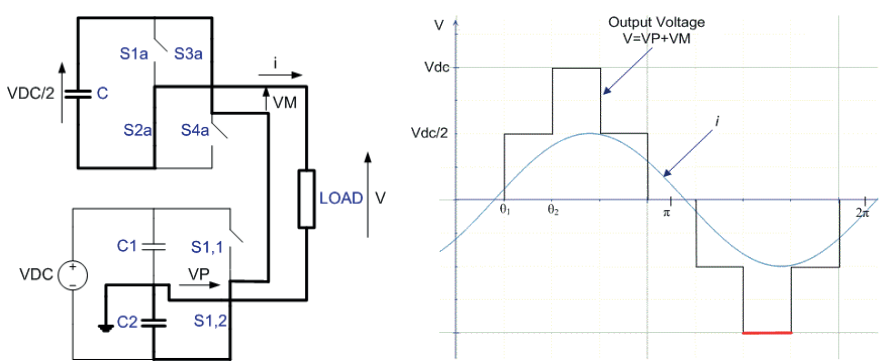

Fig. 6. Generation of an output voltage $\mathrm{V}=-\mathrm{VDC}$

In order to ensure proper operation of the converter, the voltage of capacitor $\mathrm{C}$ must be kept constant at the level of $+\mathrm{VDC} / 2$. Capacitor voltage depends on capacitors current flow in each voltage state and power factor of the load. In order to examine charging and discharging states of the capacitor three figures for a different power factor of the load are depicted in Figs. 7-9. Symbols used in figures denote respectively:

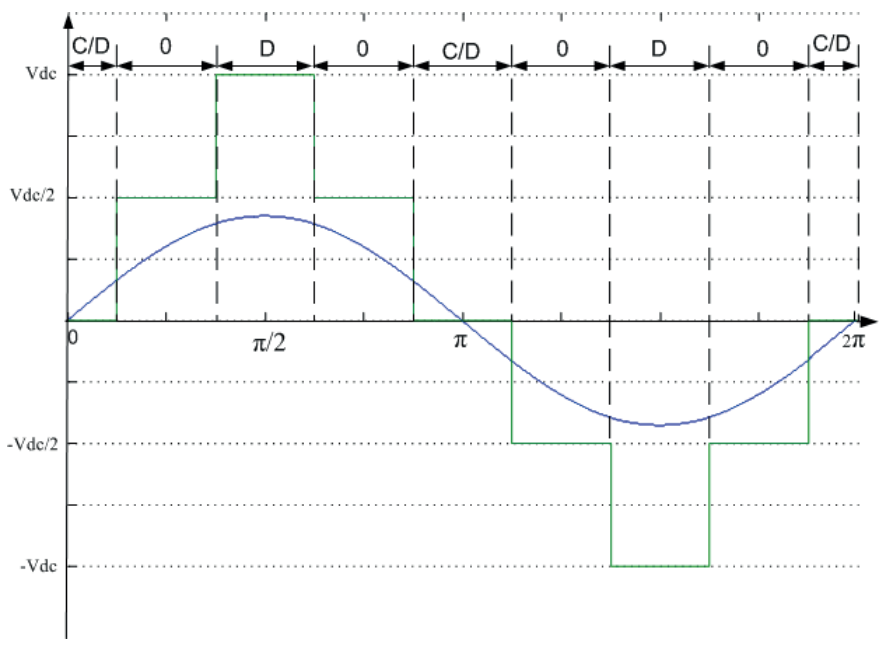

Fig. 7. Capacitor charging and discharging states for phase displacement angle $\varphi=0$

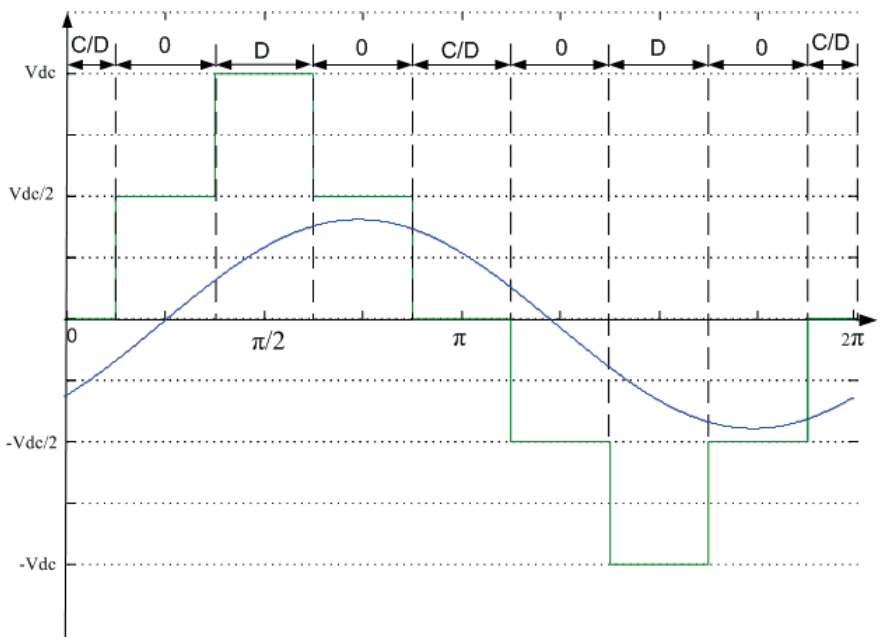

Fig. 8. Capacitor charging and discharging states for phase displacement angle $\varphi=\pi / 4$

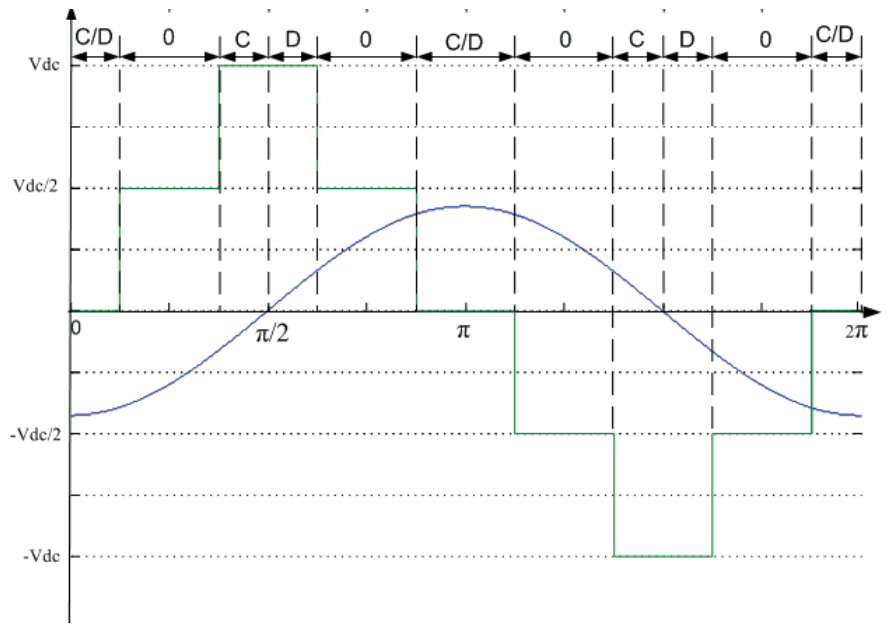

Fig. 9. Capacitor charging and discharging states for phase displacement angle $\varphi=\pi / 4$

$\mathrm{C}$ - charging state, $\mathrm{D}$ - discharging state. $\mathrm{C} / \mathrm{D}$ - charging or discharging state depending on a switch position, 0 - no charging or discharging state.

Generation of an output voltage $\mathrm{V}=0$ is the only state when it can be chosen if capacitor is charging or discharging. When load current $i$ is positive $(\boldsymbol{i}>0), \mathrm{S}_{1,1}$ is closed (so that $\mathrm{VP}=+\mathrm{VDC} / 2$ ) and $\mathrm{S}_{2 \mathrm{a}}, \mathrm{S}_{3 \mathrm{a}}$ are closed (so that $\mathrm{VM}=-\mathrm{VDC} / 2$ ), then capacitor current is positive $\left(i_{c}=i\right)$ and capacitor is charging. On the other hand, if $\mathrm{S}_{1,2}$ is closed (so that $\mathrm{VP}=-\mathrm{VDC} / 2$ ) and $\mathrm{S}_{1 \mathrm{a}}, \mathrm{S}_{4 \mathrm{a}}$ are closed (so that $\mathrm{VM}=+\mathrm{VDC} / 2$ ), capacitor current is negative $\left(i_{c}=-i\right)$ and capacitor is discharging. For the generation of an output voltage $\mathrm{V}=+\mathrm{VDC} / 2(\mathrm{VP}=+\mathrm{VDC} / 2$ and $\mathrm{VM}=0)$ and $\mathrm{V}=-\mathrm{VDC} / 2(\mathrm{VP}=-\mathrm{VDC} / 2$ and $\mathrm{VM}=0)$, capacitor current always equals zero $\left(i_{c}=0\right)$ regardless of the power factor of the load. For a generation of an output voltage $\mathrm{V}=+\mathrm{VDC}(\mathrm{VP}=+\mathrm{VDC} / 2$ and $\mathrm{VM}=+\mathrm{VDC} / 2)$ or $\mathrm{V}=-\mathrm{VDC}$ $(\mathrm{VP}=-\mathrm{VDC} / 2$ and $\mathrm{VM}=-\mathrm{VDC} / 2)$, capacitor current can be positive when load current is negative $\left(i_{c}>0\right.$ when $\left.i<0\right)$ and then capacitor is charging. During this state charging and discharging cannot be chosen; it depends on a power factor of a load. When phase displacement angle equals $0(\varphi=0)$ charging is possible only during the generation of an output voltage $\mathrm{V}=0$. Since load current $i$ during this state is small, charging capability is small. Therefore, capacitor voltage regulation is very limited. When phase displacement grows to $\pi / 4(\varphi=\pi / 4)$, the load current value is bigger during zero load voltage, so charging capability increases. When phase displacement equals $\pi / 2(\varphi=\pi / 2)$, charging capability reaches its maximum.

During zero output voltage load current reaches its peak. Additionally during generation of a load voltage $\mathrm{V}=+\mathrm{VDC}$ or $\mathrm{V}=-\mathrm{VDC}$ when load current is negative $(i<0)$ capacitor is charging. The ability to regulate capacitor voltage to a level $\mathrm{VDC} / 2$ affects the value of the highest load voltage. When the power factor of the load is close to 1 , phase displacement is close to $0(\varphi=0)$. That means the possible average charging current is small. If the output voltage grows, then the time in which output voltage level reaches +VDC or -VDC will 
increase. The longer the highest levels of output voltage are generated, the greater is an average discharge current. When the output voltage surpasses a certain level, the average discharge current becomes greater than the average charging current and the capacitor starts discharging at each period of time. In this case, capacitor voltage cannot be kept at a constant level of $\mathrm{VDC} / 2$. When power factor of the load goes down to 0 , phase displacement $\varphi$ grows to $\pi / 2$. That means the amount of possible average charging current is growing. At displacement $\varphi$ equal to $\pi / 2$ the amount of possible average charging current reaches maximum, therefore possible output voltage level grows to its maximum possible level. As a conclusion it can be said that the highest output voltage level of the converter depends on the displacement power factor of the load.

\section{Mathematical model of $5 \mathrm{LCHB}$ converter}

Considering the unitary vector $a=e^{j \frac{2 \pi}{3}}$, which represents the $120^{\circ}$ phase displacement between the phases, the output voltage vector can be defined as:

$$
\mathbf{v}=\frac{2}{3}\left(\mathrm{v}_{\mathrm{aN}}+\mathrm{av}_{\mathrm{bn}}+\mathrm{a}^{2} \mathrm{v}_{\mathrm{cN}}\right)
$$

where:

$$
\begin{aligned}
& \mathrm{v}_{\mathrm{aN}}=\mathrm{S}_{\mathrm{b}} \mathrm{V}_{\mathrm{dc}}, \\
& \mathrm{v}_{\mathrm{bN}}=\mathrm{S}_{\mathrm{a}} \mathrm{V}_{\mathrm{dc}}, \\
& \mathrm{v}_{\mathrm{cN}}=\mathrm{S}_{\mathrm{c}} \mathrm{V}_{\mathrm{dc}} .
\end{aligned}
$$

Voltage levels $\mathrm{Sa}, \mathrm{Sb}, \mathrm{Sc}$ for phases a, b, c are defined respectively:

$$
S_{a}=\left\{\begin{array}{c}
1.5 \text { for } S_{1,1}, S_{2 a}, S_{3 a} \text { on; } S_{1,2}, S_{1 a}, S_{4 a} \text { off } \\
1 \text { for } S_{1,1}, S_{1 a}, S_{3 a} \text { on; } S_{1,2}, S_{2 a}, S_{4 a} \text { off } \\
1 \text { for } S_{1,1}, S_{2 a}, S_{4 a} \text { on; } S_{1,2}, S_{1 a}, S_{3 a} \text { off } \\
0.5 \text { for } S_{1,2}, S_{2 a}, S_{3 a} \text { on; } S_{1,1}, S_{1 a}, S_{4 a} \text { off } \\
0 \text { for } S_{1,2}, S_{2 a}, S_{4 a} \text { on; } S_{1,1}, S_{1 a}, S_{3 a} \text { off } \\
0 \text { for } S_{1,2}, S_{1 a}, S_{3 a} \text { on; } S_{1,1}, S_{2 a}, S_{4 a} \text { off } \\
-0.5 \text { for } S_{1,2}, S_{1 a}, S_{4 a} \text { on; } S_{1,1}, S_{2 a}, S_{3 a} \text { off }
\end{array},\right.
$$

$$
S_{b}=\left\{\begin{array}{c}
1.5 \text { for } S_{1,3}, S_{2 b}, S_{3 b} \text { on } S_{1,4}, S_{1 b}, S_{4 b} \text { off } \\
1 \text { for } S_{1,3}, S_{1 b}, S_{3 b} \text { on; } S_{1,4}, S_{2 b}, S_{4 b} \text { off } \\
1 \text { for } S_{1,3}, S_{2 b}, S_{4 b} \text { on } S_{1,4}, S_{1 b}, S_{3 b} \text { off } \\
0.5 \text { for } S_{1,4}, S_{2 b}, S_{3 b} \text { on } ; S_{1,3}, S_{1 b}, S_{4 b} \text { off } \\
0 \text { for } S_{1,4}, S_{2 b}, S_{4 b} \text { on; } S_{1,3}, S_{1 b}, S_{3 b} \text { off } \\
0 \text { for } S_{1,4}, S_{1 b}, S_{3 b} \text { on; } S_{1,3}, S_{2 b}, S_{4 b} \text { off } \\
-0.5 \text { for } S_{1,4}, S_{1 b}, S_{4 b} \text { on } ; S_{1,3}, S_{2 b}, S_{3 b} \text { off }
\end{array}\right.
$$

All combination of voltage states $\mathrm{Sa}, \mathrm{Sb}, \mathrm{Sc}$ give $125 \mathrm{vec}-$ tors total and 61 with different values. All available vectors on the complex plane are shown in Fig. 10.

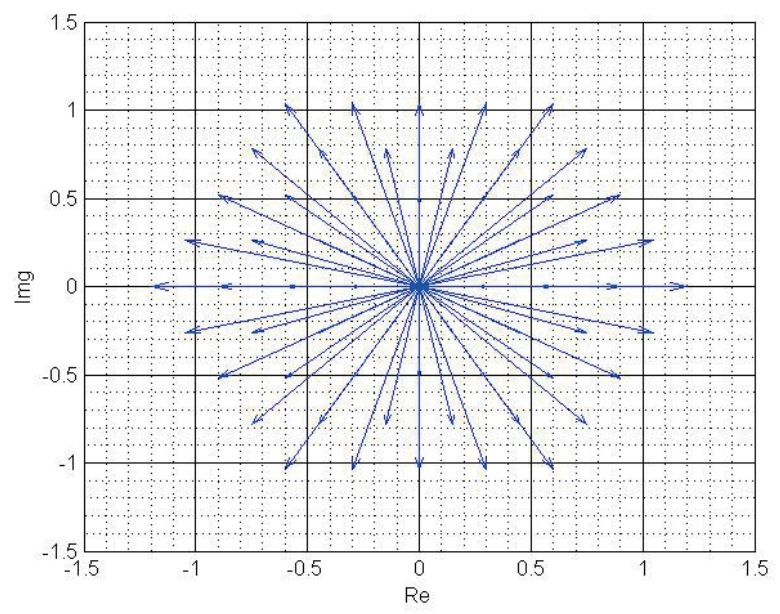

Fig. 10. Voltage vectors on a complex plane

Capacitor currents can be defined as:

$$
i_{c x}=H_{x} i_{x}
$$

$\mathrm{H}_{\mathrm{x}}$ is a function of output voltage level $\mathrm{S}_{\mathrm{x}}$ :

$$
H_{x}=\left\{\begin{array}{c}
1 \text { for } S_{x}=-0.5 \text { lub } 0.5 \\
0 \text { for } S_{x}=1 \text { lub } 0 \\
-1 \text { for } S_{x}=1.5
\end{array},\right.
$$

where $\mathrm{x}=\mathrm{a}, \mathrm{b}, \mathrm{c}$.

\section{Predictive current control}

Model predictive current control (MPC) strategy proposed in this paper uses a discrete model of a converter and load to predict the behavior of the system for each possible voltage vector generated by the converter. The voltage vector that minimizes a cost function is selected and applied during a whole sampling interval. According to [7-9], the current of a sample $\mathrm{k}+1$ for the vectorial model of the RLE load from Fig. 1 with a sample time $T_{s}$ can be expressed as:

$\mathrm{i}^{\mathrm{p}}(\mathrm{k}+1)=\left(1-\frac{\mathrm{RT}_{\mathrm{s}}}{\mathrm{L}}\right) \mathrm{i}(\mathrm{k})+\frac{\mathrm{T}_{\mathrm{s}}}{\mathrm{L}}(\mathrm{v}(\mathrm{k})-\mathrm{e}(\mathrm{k}))$. 
Predicted capacitor voltage according to [7] can be expressed as:

$$
V_{c x}^{p}(\mathrm{k}+1)=V_{c x}(\mathrm{k})+\frac{1}{C_{c x}} i_{c x}(k) T_{s}
$$

where $\mathrm{x}=\mathrm{a}, \mathrm{b}, \mathrm{c}$.

In order to select the optimal voltage vector, it is necessary calculate the predicted current for all 125 voltage vectors, and then evaluate cost function $g$ which is a sum of current errors and capacitor voltage errors:

$$
\begin{aligned}
& g=\left|\mathrm{i}_{\text {aref }}-\mathrm{i}_{\alpha}^{\mathrm{p}}\right|+\left|\mathrm{i}_{\beta \text { ref }}-\mathrm{i}_{\beta}\right|+\lambda \mid \mathrm{V}_{\text {caref }}-\mathrm{V}^{\mathrm{p}} \text { ca } \mid+ \\
& +\lambda\left|\mathrm{V}_{\text {cbref }}-\mathrm{V}_{\mathrm{cb}}^{\mathrm{p}}\right|+\lambda\left|\mathrm{V}_{\mathrm{ccref}}-\mathrm{V}_{\mathrm{cc}}^{\mathrm{p}}\right|
\end{aligned}
$$

where: $i_{\text {aref }}, i_{\beta r e f}-\alpha, \beta$ components of the reference current vector, $\mathrm{i}_{\alpha}, \mathrm{i}_{\beta}-\alpha, \beta$ components of the prediction current from (10), $\mathrm{V}_{\text {caref }}, \mathrm{V}_{\text {cbref }}, \mathrm{V}_{\text {ccref }}$ - reference voltage of capacitors $\mathrm{C}_{\mathrm{a}}, \mathrm{C}_{\mathrm{b}}, \mathrm{C}_{\mathrm{c}}$, $\mathrm{V}^{\mathrm{p}}{ }_{\mathrm{ca}}, \mathrm{V}_{\mathrm{cb}}^{\mathrm{p}}, \mathrm{V}^{\mathrm{p}}{ }_{\mathrm{cc}}$ - prediction voltage of capacitors $\mathrm{C}_{\mathrm{a}}, \mathrm{C}_{\mathrm{b}}, \mathrm{C}_{\mathrm{c}}$, $\lambda$ - weighting factor that handles relation between terms dedicated to current tracking and capacitor voltage balancing. Parameter $\lambda$ was set for 0.1 . According to simulation experiments this value ensures a good quality waveforms in a wide range of phase displacement angle $\varphi$. Optimal setting of parameter $\lambda$ is out of scope of this paper. Capacitor voltage errors in a cost function provide capacitor voltage regulation. The voltage vector that minimizes the cost function will be chosen as an optimal vector. The whole algorithm of MPC is illustrated in Fig. 11.

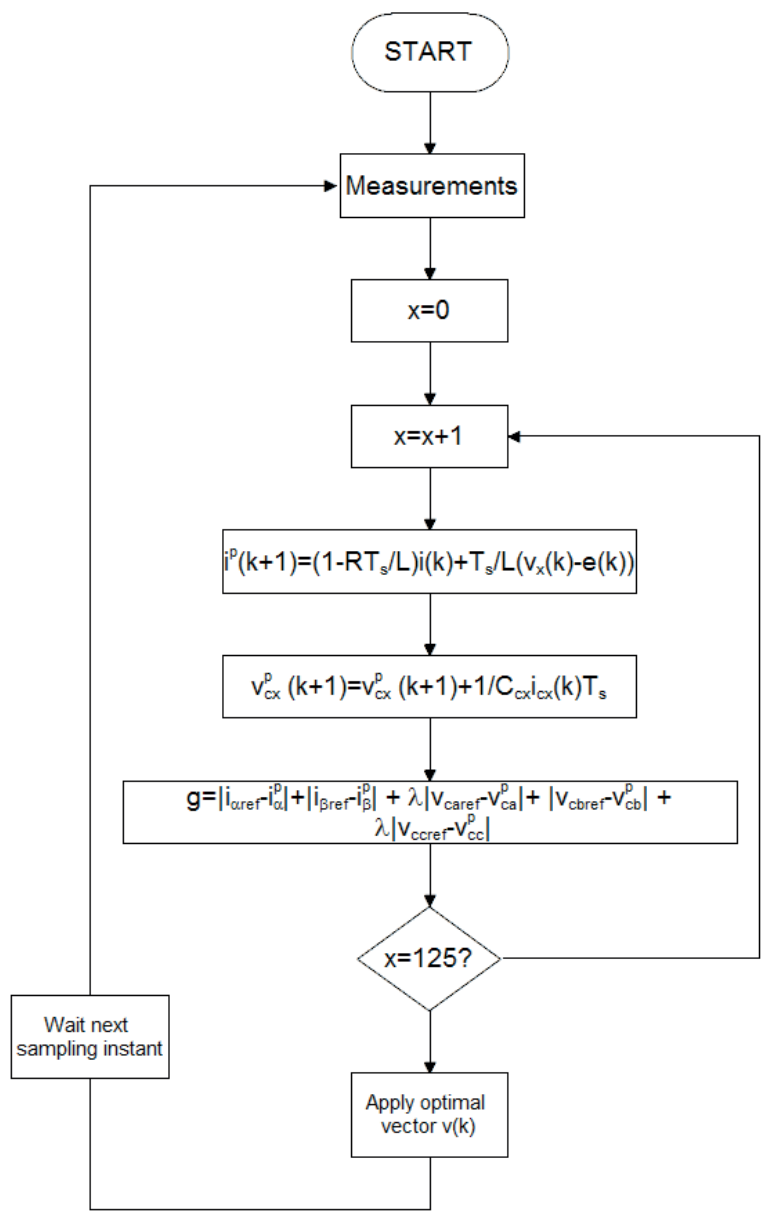

Fig. 11. MPC control algorithm

\section{Simulation results}

Simulation of 5LCHB converter with model predictive control were performed in the Matlab/Simulink environment. The system parameter used for the simulation were respectively: $\mathrm{DC}$ source voltage VDC $=100 \mathrm{~V}, \mathrm{C}_{\mathrm{a}}, \mathrm{C}_{\mathrm{b}}, \mathrm{C}_{\mathrm{c}}=4000 \mu \mathrm{F}, \mathrm{R}, \mathrm{L}$ - values depend on a phase displacement angle $\varphi$. The capacitance value was chosen experimentally. The $4000 \mu \mathrm{F}$ value gives the highest boosting capability and highest linear range of operation for a given VDC and reference currents. Experimental measurements of maximum modulation index and maximum boosting ratio for different capacitance values are presented in Table 1.

Table 1

Maximum modulation index and boosting ratio

\begin{tabular}{|c|c|c|}
\hline $\begin{array}{c}\text { Capacitance value } \\
{[\mathrm{uF}]}\end{array}$ & $\begin{array}{c}\text { Maximum } \\
\text { modulation index } \mathrm{m}\end{array}$ & $\begin{array}{c}\text { Boosting } \\
\text { ratio }\end{array}$ \\
\hline 500 & 1.5 & 1.3 \\
\hline 1000 & 1.6 & 1.39 \\
\hline 4000 & 2 & 1.74 \\
\hline 7000 & 2 & 1.74 \\
\hline
\end{tabular}

For capacitance values $500 \mu \mathrm{F}$ and $1000 \mu \mathrm{F}$, the linear region of operation is much smaller than for $4000 \mu \mathrm{F}$. Larger capacitance of $7000 \mu \mathrm{F}$ does not extend linear region, so capacitance 4000 $\mu \mathrm{F}$ was chosen as the optimal value.

All simulation were performed for a sampling time $\mathrm{T}_{\mathrm{s}}=200 \mu \mathrm{s}$. Phase voltages and currents for different modulation indexes and phase displacement angles of the load are depicted in Figs. 12-17. Modulation index definition used for the simulation is [9]:

$$
m=\frac{V_{1}}{V_{d c} / 2},
$$

where $\mathrm{V}_{1}$ is the 1 st order harmonic of the output phase voltage.
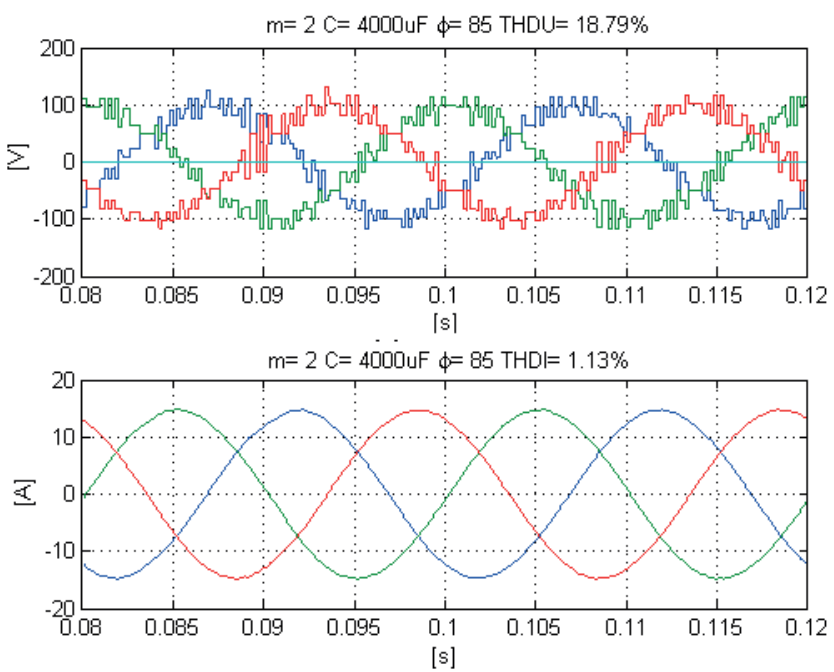

Fig. 12. Voltages $V_{a n}, V_{b n}, V_{c n}$ (top), currents $i_{a}, i_{b}$, $i_{c}$ (bottom) for $\mathrm{m}=2, \mathrm{e}_{\mathrm{a}}, \mathrm{e}_{\mathrm{b}}, \mathrm{e}_{\mathrm{c}}=0$ and $\varphi=85$ 
Figure 12 presents waveforms for modulation index $\mathrm{m}=2$ at phase displacement angle $\varphi=85$. It is a maximum available value of this parameter. When modulation index exceeds this value, converter is losing its capacity to regulate capacitor voltage level to VDC/2 and output voltage and current gets distorted. Example waveform for modulation index $\mathrm{m}=2.2$ is depicted in Fig. 18. Figures 14 and 16 present the maximum modulation index waveforms for $\varphi=50$ and $\varphi=15$, respectively.

Maximum output voltage of 5LCHB converter for all presented phase displacement angles is always greater than the output voltage of a classical 2-level 3 phase converter. Classical converter can reach maximum value of modulation in$\operatorname{dex} \mathrm{m}=1.15$. For parameters used in simulation maximum output phase voltage measured was $100 \mathrm{~V}$ whilst a classical converter can reach maximum $\mathrm{VDC} / \sqrt{3}=57.73 \mathrm{~V}$. That bring boosting ratio 1.73 . For $\varphi=15$ boosting ratio equals 1.12 .
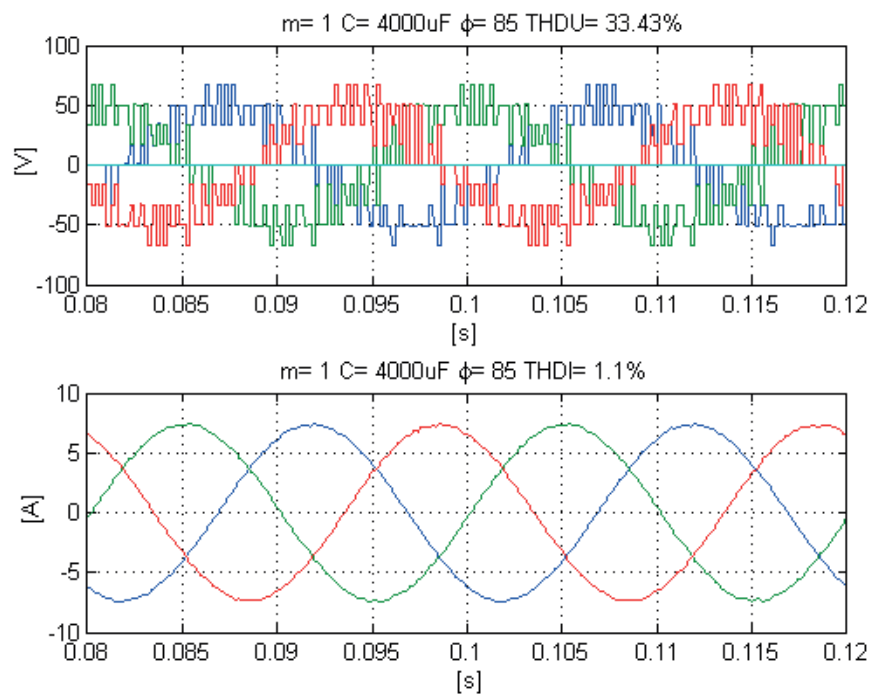

Fig. 13. Voltages $V_{a n}, V_{b n}, V_{c n}$ (top), currents $i_{a}, i_{b}, i_{c}$ (bottom) for $\mathrm{m}=1, \mathrm{e}_{\mathrm{a}}, \mathrm{e}_{\mathrm{b}}, \mathrm{e}_{\mathrm{c}}=0$ and $\varphi=85$
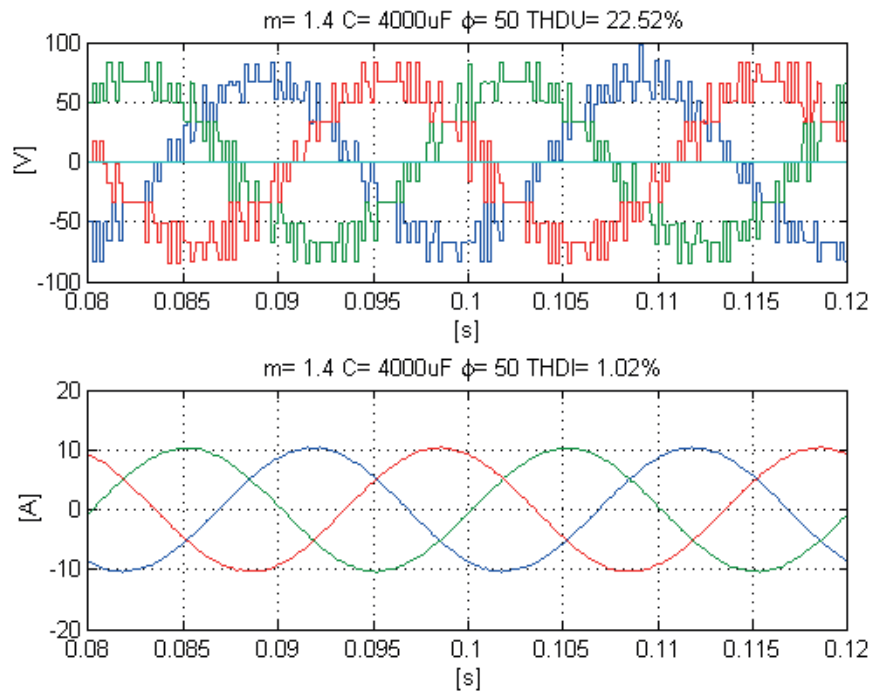

Fig. 14. Voltages $V_{a n}, V_{b n}, V_{c n}$ (top), currents $i_{a}, i_{b}, i_{c}$ (bottom) for $\mathrm{m}=1.4, \mathrm{e}_{\mathrm{a}}, \mathrm{e}_{\mathrm{b}}, \mathrm{e}_{\mathrm{c}}=0$ and $\varphi=50$
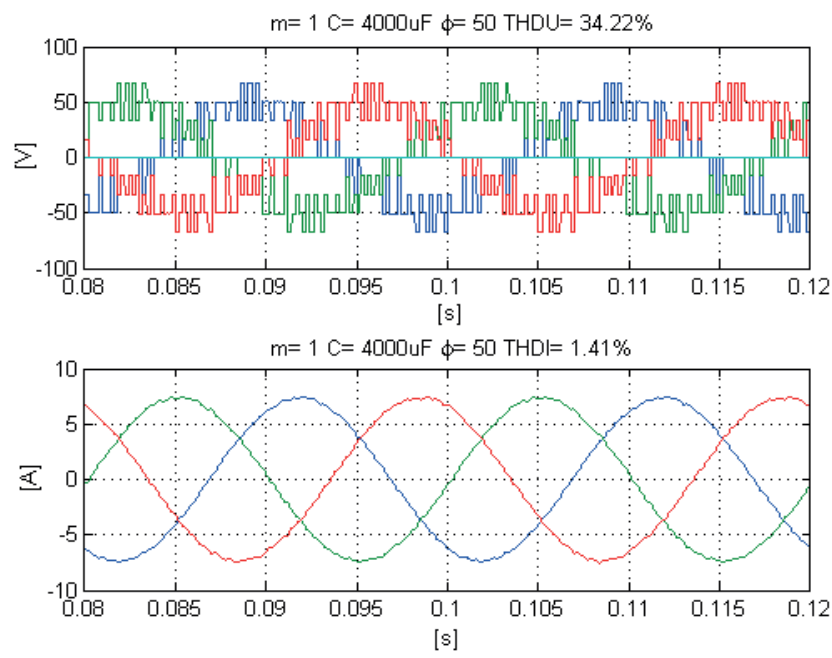

Fig. 15. Voltages $V_{a n}, V_{b n}, V_{c n}$ (top), currents $i_{a}, i_{b}$, $i_{c}$ (bottom) for $\mathrm{m}=1, \mathrm{e}_{\mathrm{a}}, \mathrm{e}_{\mathrm{b}}, \mathrm{e}_{\mathrm{c}}=0$ and $\varphi=50$
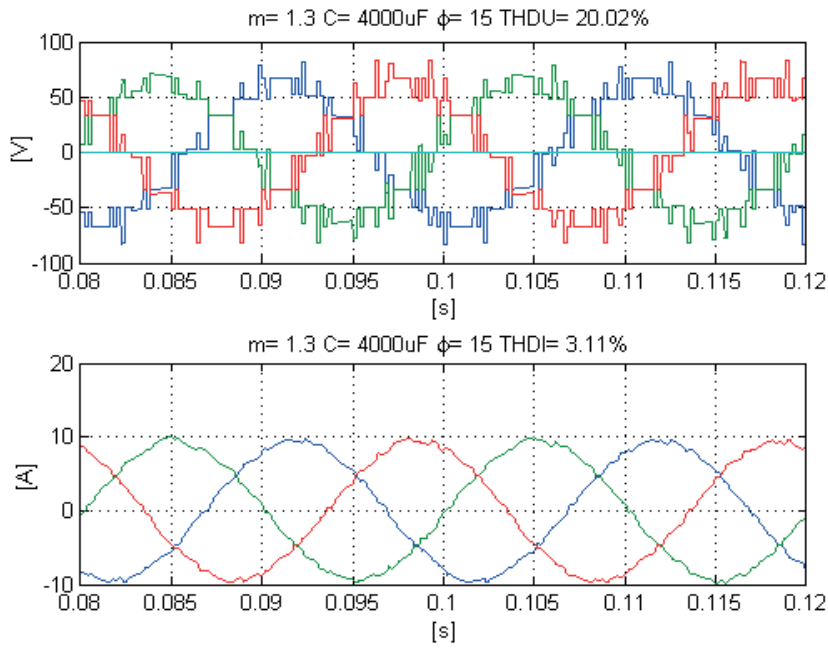

Fig. 16. Voltages $V_{a n}, V_{b n}, V_{c n}$ (top), currents $i_{a}, i_{b}, i_{c}$ (bottom) for $\mathrm{m}=1.3, \mathrm{e}_{\mathrm{a}}, \mathrm{e}_{\mathrm{b}}, \mathrm{e}_{\mathrm{c}}=0$ and $\varphi=15$
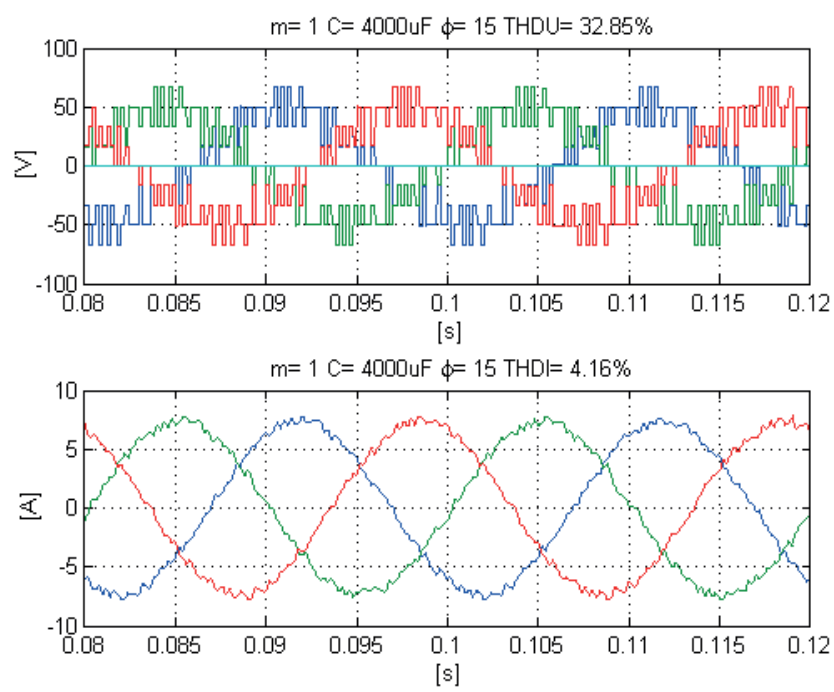

Fig. 17. Voltages $V_{a n}, V_{b n}, V_{c n}$ (top), currents $i_{a}, i_{b}$, $i_{c}$ (bottom) for $\mathrm{m}=1, \mathrm{e}_{\mathrm{a}}, \mathrm{e}_{\mathrm{b}}, \mathrm{e}_{\mathrm{c}}=0$ and $\varphi=15$ 

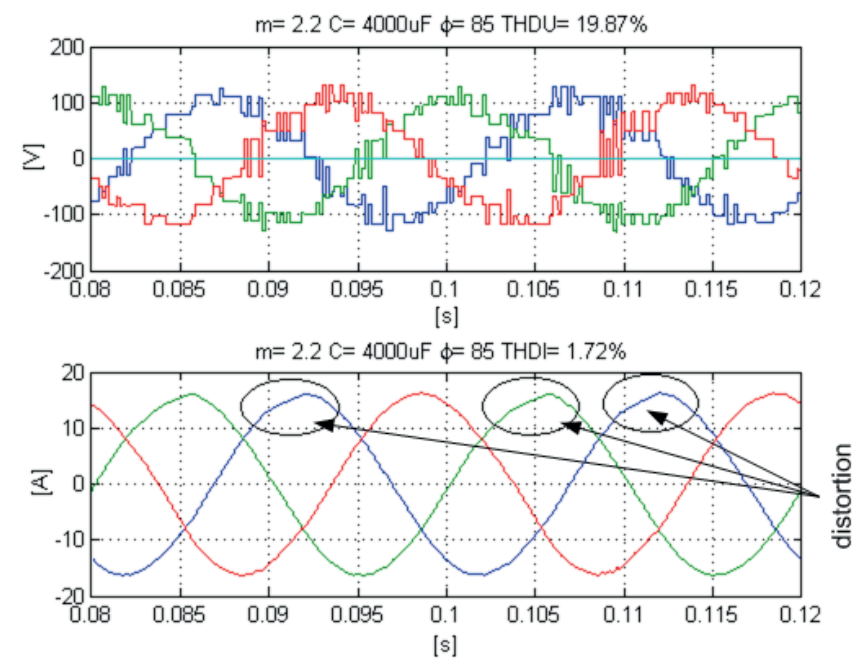

Fig. 18. Distorted voltages $\mathrm{V}_{\mathrm{an}}, \mathrm{V}_{\mathrm{bn}}, \mathrm{V}_{\mathrm{cn}}$ (top) and distorted currents ia, ib, ic (bottom) for $\mathrm{m}=2.2$ and $\varphi=85$

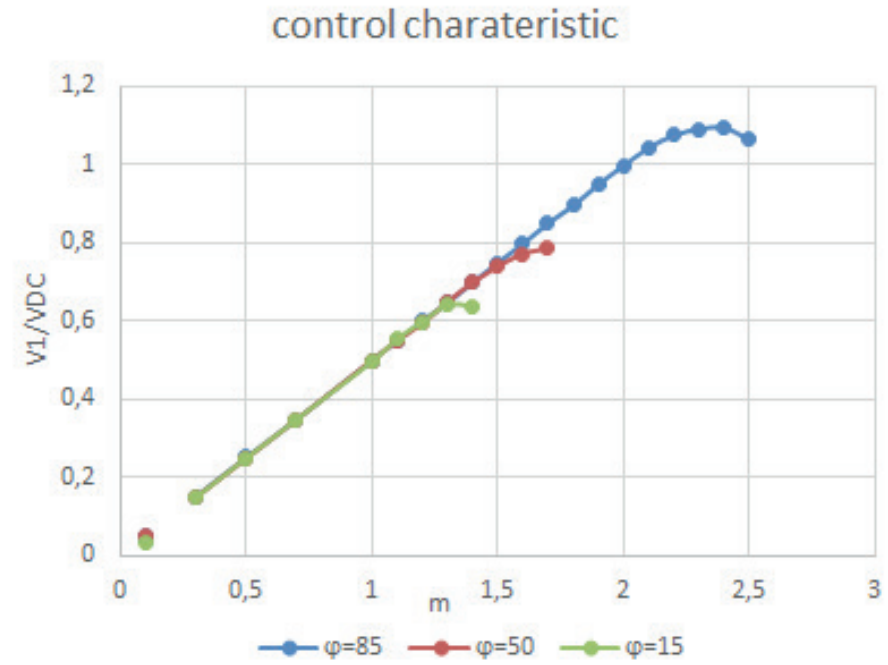

Fig. 19. Control characteristic of $5 \mathrm{LCHB}$ converter for $\varphi=15, \varphi=50$, $\varphi=85$

\section{THDU}

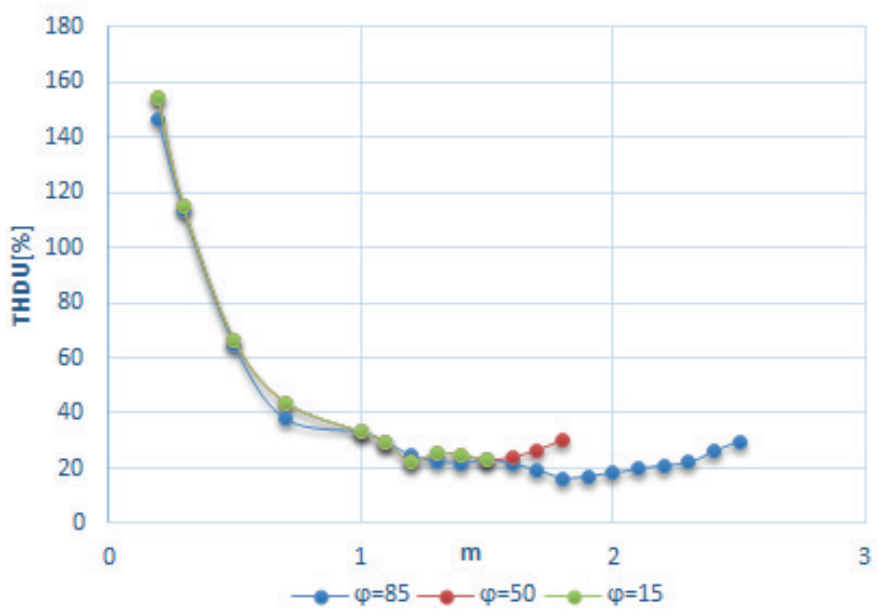

Fig. 20. THDI of phase current for $\varphi=15, \varphi=50, \varphi=85$
Measuring the 1st order harmonic of the output phase voltage $\mathrm{V}_{1}$ for different modulation index values control characteristic for 5LCHB was designated (Fig. 19). Figs. 20 and 21 show THD of phase voltage and phase current for different $\varphi$. Examplary waveforms of output voltage and current with, $\mathrm{e}_{\mathrm{a}}$, $\mathrm{e}_{\mathrm{b}}, \mathrm{e}_{\mathrm{c}}=25 \mathrm{~V}$ are depicted in Figs. 22 and 23. Only one phase ea is shown for a better clarity.

THDI

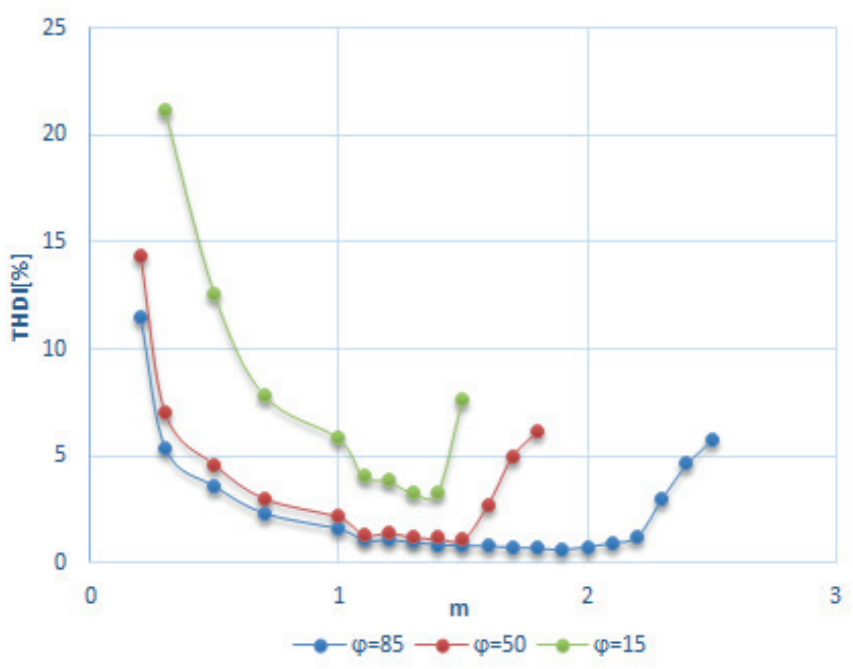

Fig. 21. THDI of 5LCHB converter for $\varphi=15, \varphi=50, \varphi=85$
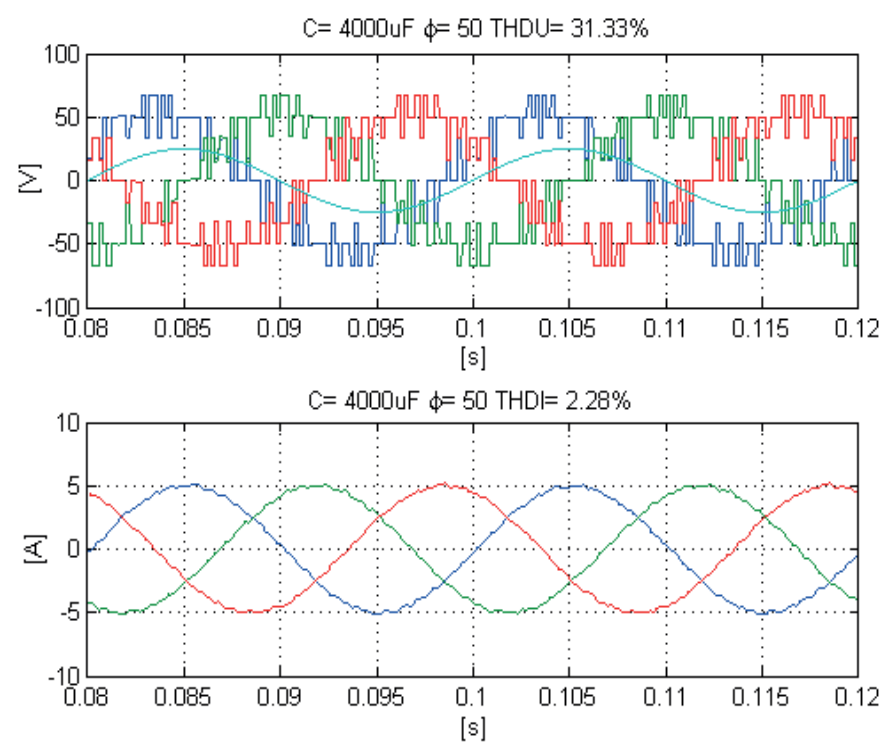

Fig. 22. Voltages $V_{a n}, V_{b n}, V_{c n}$ (top), currents $i_{a}, i_{b}, i_{c}$ (bottom) for Iref $=5 \mathrm{~A}, \mathrm{e}_{\mathrm{a}}, \mathrm{e}_{\mathrm{b}}, \mathrm{e}_{\mathrm{c}}=25 \mathrm{~V}$ and $\varphi=50$

The presented predictive controller successfully regulates capacitor voltage. In order to limit capacitor voltage variations, a cost function was set to reach infinite value for every voltage vector that would exceed a capacitor voltage limits of 40 

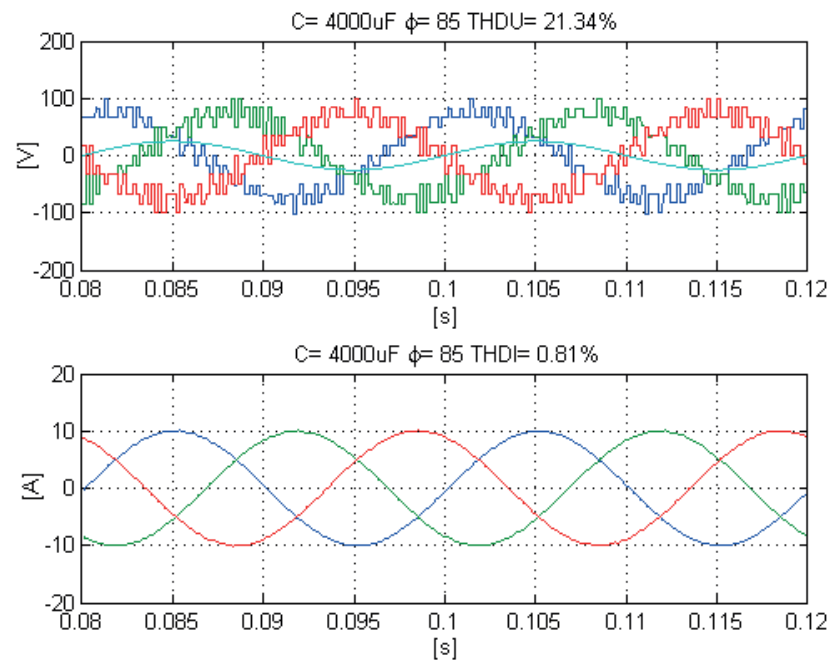

Fig. 23. Voltages $V_{a n}, V_{b n}, V_{c n}$ (top), currents $i_{a}, i_{b}, i_{c}$ (bottom) for Iref $=10, e_{a}, e_{b}, e_{c}=25 V$ and $\varphi=85$

V-60 V. Fig. 24. shows an example of capacitor voltage and current for $m=1.6$ and $\varphi=85$. It can be seen that capacitor voltage resolves around $50 \mathrm{~V}$ level with maximum $5 \mathrm{~V}$ voltage drop.
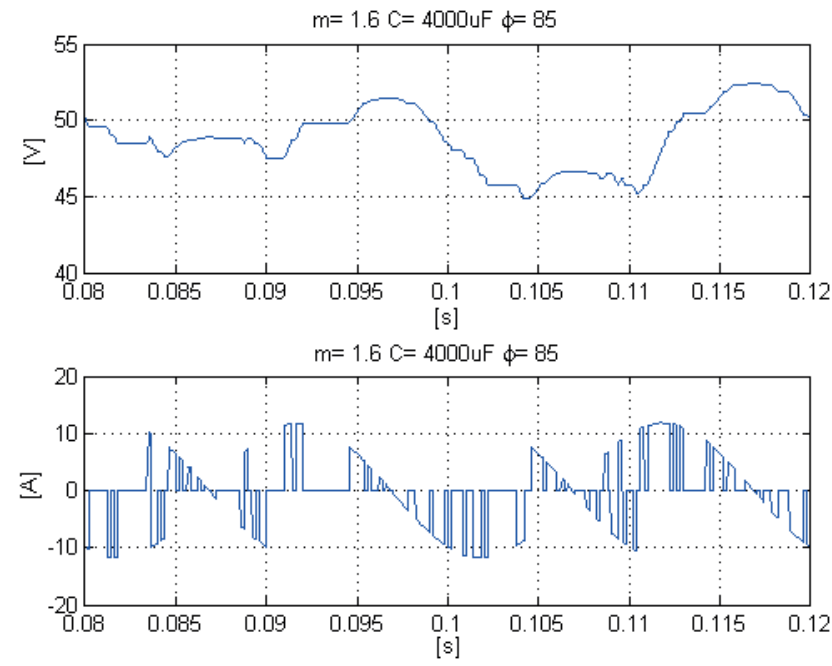

Fig. 24. Voltage (top) and current (bottom) of capacitor $C_{a}$ for $m=1.6$, $\mathrm{e}_{\mathrm{a}}, \mathrm{e}_{\mathrm{b}}, \mathrm{e}_{\mathrm{c}}=0$ and $\varphi=85$

When the converter reaches its maximum modulation index, the capacitors average voltage level goes down and voltage drop reaches $10 \mathrm{~V}$ (Fig. 25). When modulation index reaches $\mathrm{m}=2.2$ average capacitor voltage level goes even further down closer to its lower limit of $40 \mathrm{~V}$ (Fig. 26). For most of the time voltage value does not reach $50 \mathrm{~V}$. That means controller lost its capability to keep voltage at level $50 \mathrm{~V}$, and output voltage and current are distorted. Regulation of capacitor voltage for $\varphi=50$ and $\varphi=15$ are depicted in Fig. 27 and Fig. 28 respectively. In order to observe capacitor voltage regulation in transient states, simulations with reference current change were
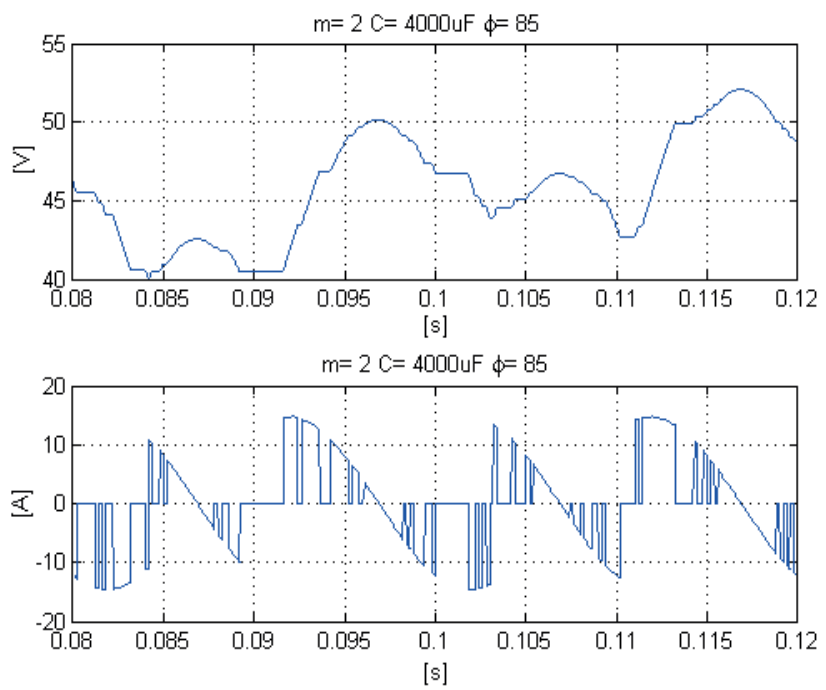

Fig. 25. Voltage (top) and current (bottom) of capacitor $\mathrm{C}_{\mathrm{a}}$ for $\mathrm{m}=2$, $\mathrm{e}_{\mathrm{a}}, \mathrm{e}_{\mathrm{b}}, \mathrm{e}_{\mathrm{c}}=0$ and $\varphi=85$
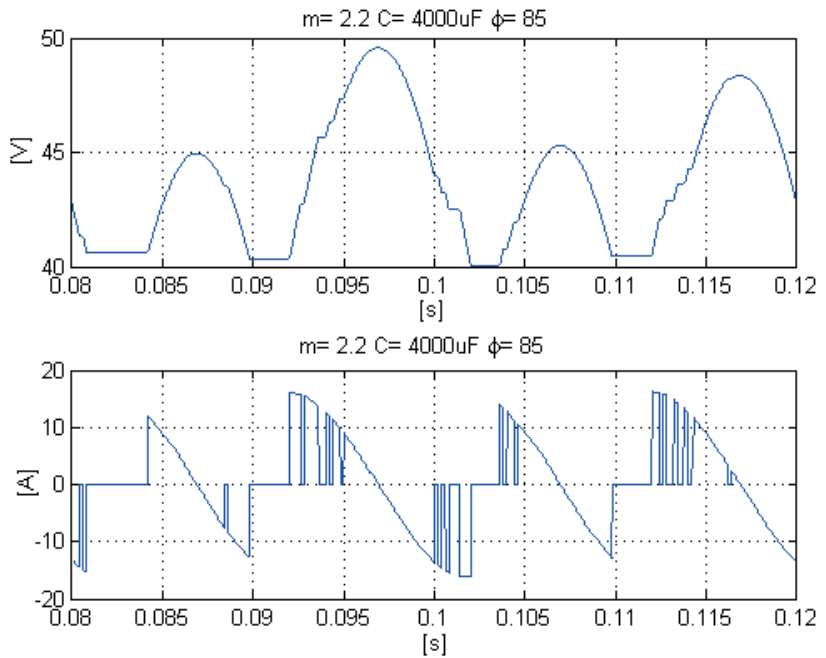

Fig. 26. Voltage (top) and current (bottom) of capacitor $\mathrm{C}_{\mathrm{a}}$ for $\mathrm{m}=2.2$, $\mathrm{e}_{\mathrm{a}}, \mathrm{e}_{\mathrm{b}}, \mathrm{e}_{\mathrm{c}}=0$ and $\varphi=85$
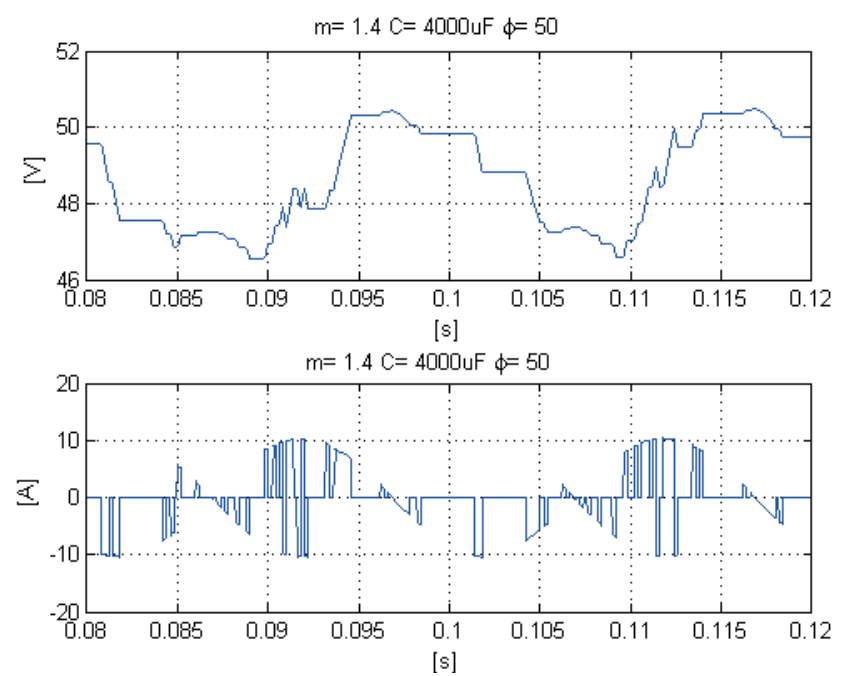

Fig. 27. Voltage (top) and current (bottom) of capacitor $\mathrm{C}_{\mathrm{a}}$ for $\mathrm{m}=1.4$, $\mathrm{e}_{\mathrm{a}}, \mathrm{e}_{\mathrm{b}}, \mathrm{e}_{\mathrm{c}}=0$ and $\varphi=50$ 

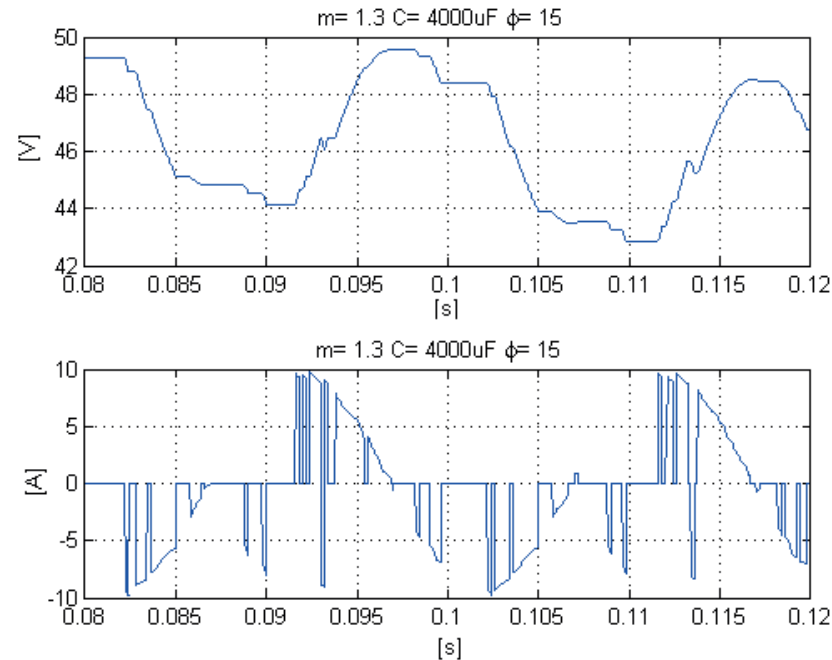

Fig. 28. Voltage (top) and current (bottom) of capacitor $\mathrm{C}_{\mathrm{a}}$ for $\mathrm{m}=1.3$, $\mathrm{e}_{\mathrm{a}}, \mathrm{e}_{\mathrm{b}}, \mathrm{e}_{\mathrm{c}}=0$ and $\varphi=15$

performed (Figs. 29-32). It can be observed that after current change at instant $\mathrm{t}=0.12 \mathrm{~s}$, the capacitor voltage drop greatly increases and after a transient the voltage get stable. Figures 24-32 confirms a successful operation of control algorithm for capacitor voltage balancing.
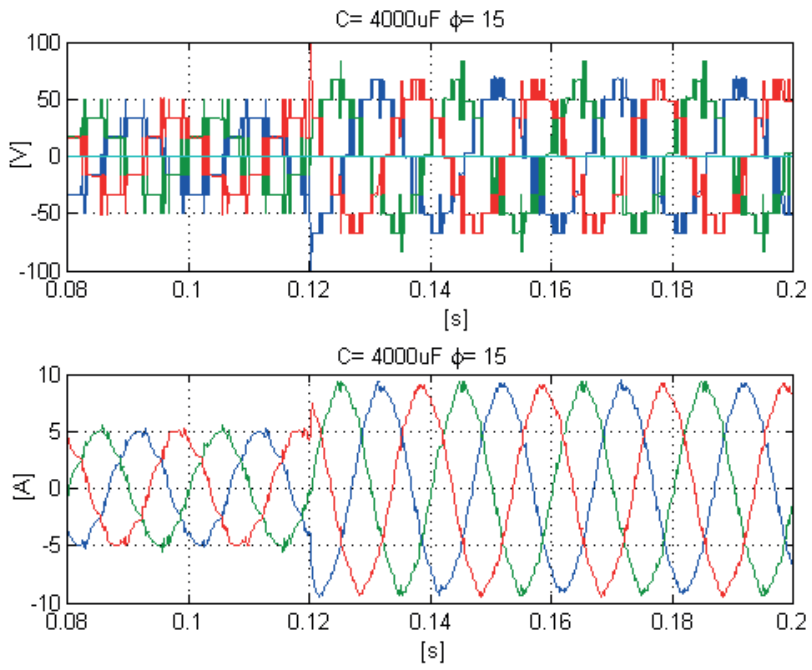

Fig. 29. Voltages $V_{a n}, V_{b n}, V_{c n}$ (top), currents $i_{a}, i_{b}, i_{c}$ (bottom) for current reference step from $5 \mathrm{~A}$ to $9 \mathrm{~A}, \mathrm{e}_{\mathrm{a}}, \mathrm{e}_{\mathrm{b}}, \mathrm{e}_{\mathrm{c}}=0$ and $\varphi=15$

As mentioned in Section 2 of this paper, the maximum load voltage depends on power factor of the load. Figure 33 depicts the maximum value of modulation index in function of angle $\varphi$. This characteristic was made for parameters mentioned in Sections 4 and 5. If modulation index exceeds the maximum value denoted by characteristic, the predictive controller loses its ability to balance capacitor voltage and output waveforms of voltage and current get distorted.
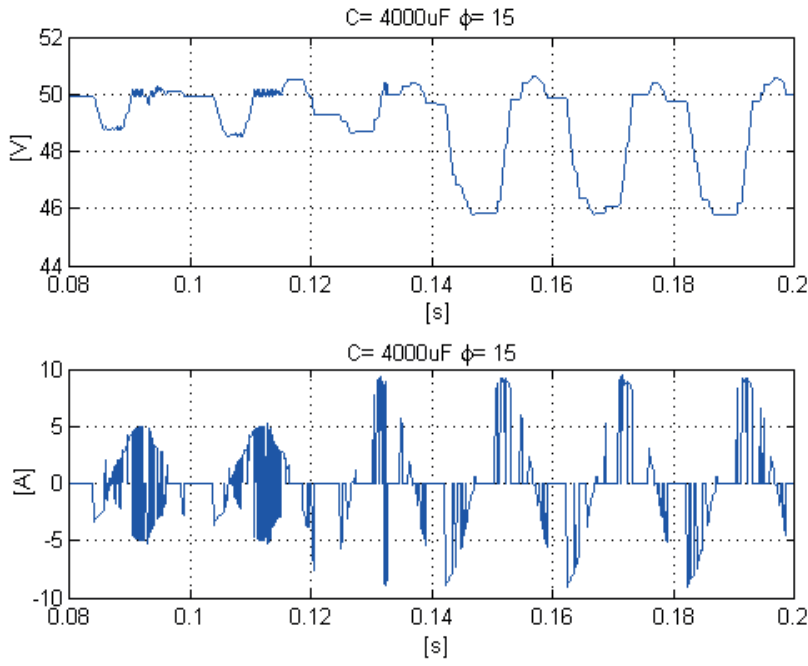

Fig. 30. Voltage (top) and current (bottom) of capacitor $\mathrm{C}_{\mathrm{a}}$ for current reference step from $5 \mathrm{~A}$ to $9 \mathrm{~A}, \mathrm{e}_{\mathrm{a}}, \mathrm{e}_{\mathrm{b}}, \mathrm{e}_{\mathrm{c}}=0$ and $\varphi=15$
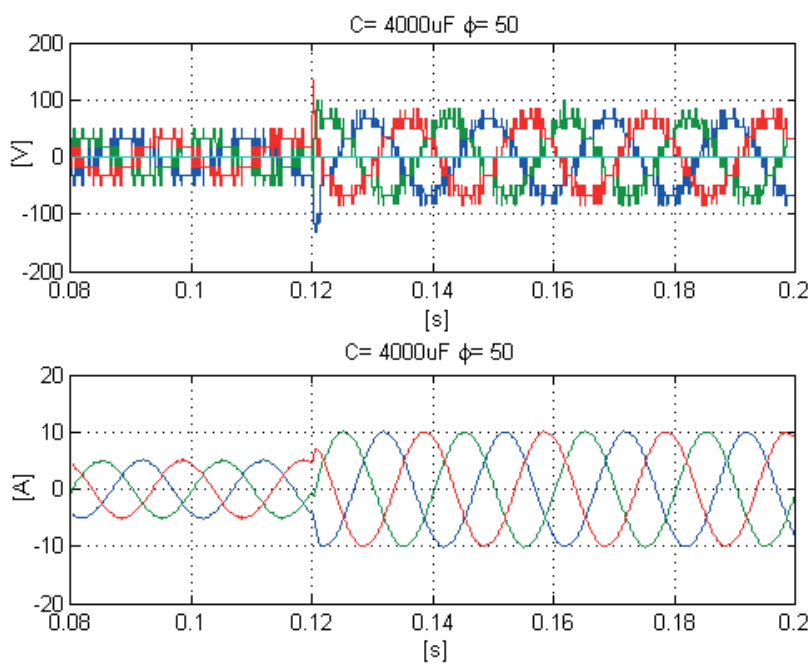

Fig. 31. Voltages $V_{a n}, V_{b n}, V_{c n}$ (top), currents $i_{a}, i_{b}$, $i_{c}$ (bottom) for current reference step from $5 \mathrm{~A}$ to $10 \mathrm{~A}, \mathrm{e}_{\mathrm{a}}, \mathrm{e}_{\mathrm{b}}, \mathrm{e}_{\mathrm{c}}=0$ and $\varphi=50$
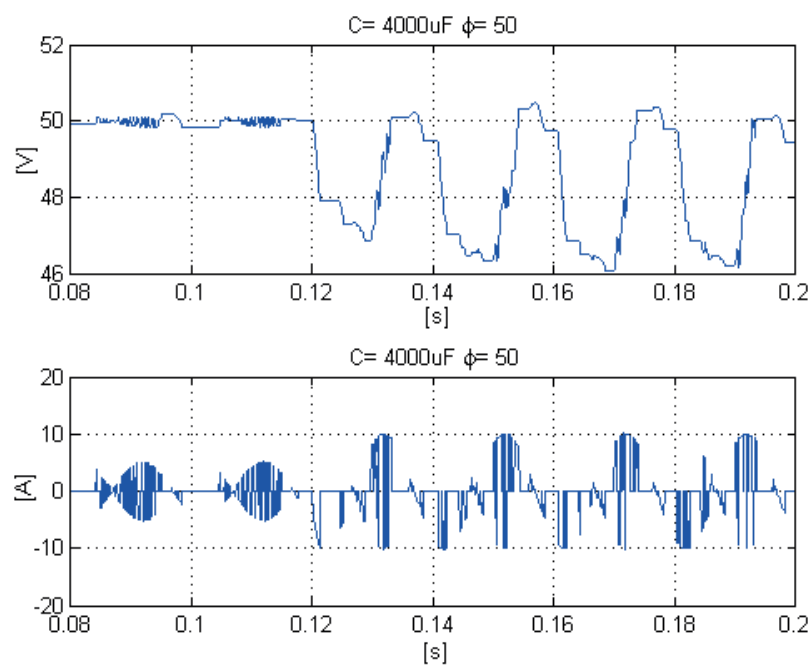

Fig. 32. Voltage (top) and current (bottom) of capacitor $C_{a}$ for current reference step from $5 \mathrm{~A}$ to $9 \mathrm{~A}, \mathrm{e}_{\mathrm{a}}, \mathrm{e}_{\mathrm{b}}, \mathrm{e}_{\mathrm{c}}=0$ and $\varphi=50$ 


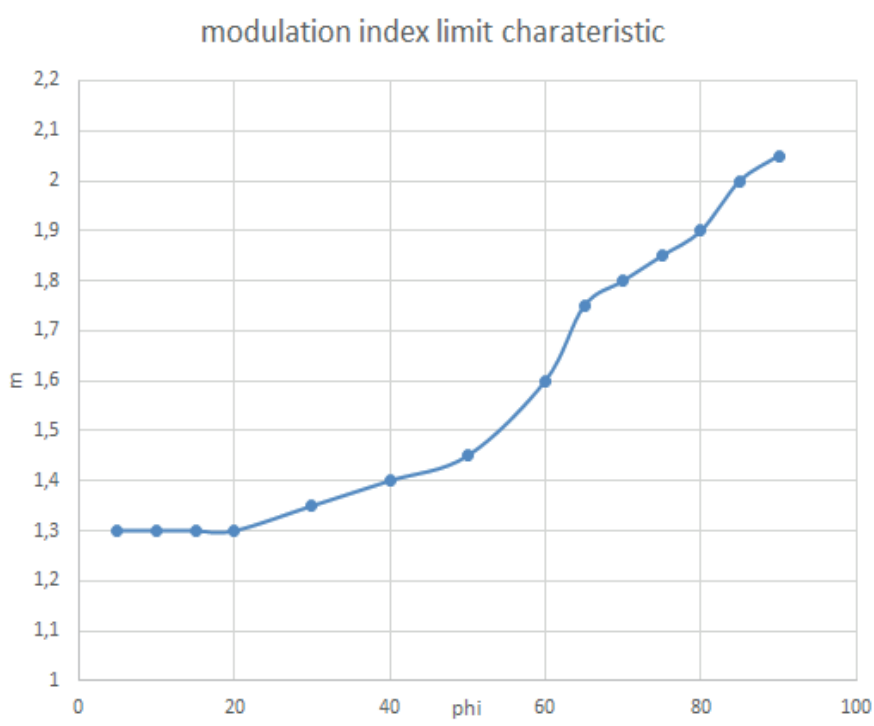

Fig. 33. Maximum modulation index versus displacement angle $\varphi$

\section{Conclusions}

This paper analyzes cascaded H-bridge 5-level converter. It uses a classical 2-level 3-phase converter with $\mathrm{H}$-bridge connected in series in each phase. A novel model predictive control (MPC) has been proposed for output current control and capacitor voltage balancing.

Utilization of MPC has the following features and advantages:

- simple solution for multilevel converter compared to other control strategies,

- elimination of PWM modulator,

- simple application of capacitor voltage balancing.

Among its disadvantages one may find:

- requirement of fast processor for on-line optimization,

- the knowledge of the load parameters being required.

Simulation studies showed that 5LCHB converter with model predictive controller has the following advantages:

- generation of boosted output voltage,

- good quality of output waveform with low THD,

- fast response to reference current changes.

The observed disadvantages are:

- a large number of switching devices,

- utilization of bulky capacitors for powering H-bridges.
Acknowledgments. This work was supported by the National Science Centre as the scientific project DEC-2014/15/N/ ST7/05067.

\section{REFERENCES}

[1] S. Kouro, M. Malinowski, K. Gopakumar, J. Pou, L. G. Franquelo, B. Wu, J. Rodriguez, M. A. Pérez, and J. I. Leon, "Recent advances and industrial applications of multilevel converters", IEEE Trans. Ind. Electron. 57 (8), 2553-2580 (2010).

[2] H. Tunia, R. Barlik, Theory of Converters, Warsaw University of Technology, Warsaw, 2003.

[3] A. Nami, F. Zare, A. Ghosh, and F. Blaabjerg, "A hybrid converter topology with series-connected symmetrical and asymmetrical diode-clamped H-bridge cells", IEEE Trans. Power Electron. 26 (1), 51-65 (2011).

[4] H. Liu, L. M. Tolbert, S. Khomfoi, B. Ozpineci, and Z. Du, "Hybrid cascaded multilevel inverter with PWM control method", IEEE Power Electron. Spec. Conf., 162-166 (2008).

[5] Z. Du, B. Ozpineci, L. M Tolbert, J. N. Chiasson, "DC-AC cascaded H-bridge multilevel boost inverter with no inductors for electric/hybrid electric vehicle applications", IEEE Industry Applications 45 (3), 963-970 (2009).

[6] S. Khomfoi and N. Praisuwanna, "A hybrid cascaded multilevel inverter for interfacing with renewable energy resources," in Proc. IEEE Intl. Power Electron. Conf., 2912-2917 (2010).

[7] J. Rodriguez and P. Cortes, Predictive Control of Power Converters and Electrical Drives, Wiley, Chichester, 2012.

[8] P. Cortes, F. Quiroz, and J. Rodriguez, "Predictive control of a grid-connected cascaded H-bridge multilevel converter", Proc. of EPE, 1-7 (2011).

[9] M.P. Kazmierkowski, R. Krishnan, F. Blaabjerg, Control in Power Electronics, Academic Press, 2002.

[10] G.P. Adam, I. Abdelsalam, S. J. Finney, D. Holliday, B. W. Williams, and J. Fletcher, " Comparison of two advanced modulation strategies for a hybrid cascaded converter", Proc. of IEEE ECCE Asia Downunder, 1334-1340 (2013).

[11] J. Li, A. Huang, S. Bhattacharya, and S. Lukic, "ETO light multi-level converters for large electric vehicle and hybrid electric vehicle drives", IEEE Veh. Power Propul. Conf., 1455-1460 (2009).

[12] M. Zygmanowski, B. Grzesik, J. Michalak, „Properties of the power conditioning system with a five-level cascaded converter and supercapacitor energy storage", Bull. Pol. Ac.: Tech. 59 (4), 525-534 (2011).

[13] T. Płatek and T. Osypiński, "Current control with asymmetrical regular sampled pulse width modulator applied in parallel active filter", Bull. Pol. Ac.: Tech. 64 (2), 287-300 (2016). 